\title{
Uniform Resource Name
}

National Cancer Institute

\section{Source}

National Cancer Institute. Uniform Resource Name. NCI Thesaurus. Code C71581.

A standardized name for a persistent, location-independent, resource identifier. 